\title{
Adequações curriculares para alunos com autismo: o que é? Como fazer?
}

\section{Curricular adaptations for students with autism: what is it? How to make?}

Henrique Arnoldo Junior (henrique.arnoldo@gmail.com)

Universidade Santa Cecília (UNISANTA)

\begin{abstract}
Resumo: O presente relato apresenta algumas Adequações Curriculares - AC, efetuadas pelo autor como professor de Matemática em uma sala de recursos para Atendimento Educacional Especializado - AEE, entre maio a dezembro de 2019, para estudantes autistas. Baseando-se no pressuposto de que não é de qualquer forma que se promove uma AC, alguns momentos pedagógicos em sala de aula foram investigados. Constatouse que a cada instante, novas AC são reinventadas, estando relacionadas a diferentes autismos. As experiências relatadas apontam o uso de recursos visuais como alternativa para compreensão dos conteúdos matemáticos, tanto por autistas como por neurotípicos. As informações obtidas apontam a necessidade de uma pedagogia visual voltada para o ensino da Matemática, e elencam uma lista de estratégias, provisórias, nunca acabadas ou definitivas, mas que se mostraram positivas para o avanço de aprendizagem destes alunos e que podem ser empregadas por diferentes profissionais da Educação para o ensino e a aprendizagem de estudantes autistas.
\end{abstract}

Palavras-chave: adequações curriculares; autismo, atendimento educacional especializado.

\begin{abstract}
The present report presents some Curricular Adaptations - CA, made by the author as a Mathematics teacher in a resource room for Specialized Educational Assistance - SEA, between May and December 2019, for autistic students. Based on the assumption that $\mathrm{CA}$ is not promoted in any way, some pedagogical moments in the classroom were investigated. It was found that at every moment, new CA are reinvented, being related to different autisms. The reported experiences point to the use of visual aids as an alternative for understanding mathematical content, both by autistic and neurotypic individuals. The information obtained points to the need for a visual pedagogy focused on the teaching of Mathematics, and lists a list of strategies, provisional, never finished or definitive, but which proved to be positive for the advancement of learning by these students and that can be used by different Education professionals for teaching and learning autistic students.
\end{abstract}

Keywords: curricular adaptations; autism; specialized educational assistance.

\section{INTRODUÇÃO}

Relatam-se algumas Adequações Curriculares - AC, efetuadas pelo autor como professor de Matemática, em salas de recursos, para Atendimento Educacional 
Especializado - AEE, para estudantes autistas ${ }^{1}$, em uma escola localizada na região metropolitana de Porto Alegre, RS. Contextualizadas ao Ensino Fundamental - EF, na segunda seção, trata-se sobre a gênese das Adaptações Curriculares - AC, que por ora são entendidas pelo autor como Adequações Curriculares, com a mesma abreviatura. No terceiro tópico, visa-se problematizar as estratégias que podem ser empregadas pelo educador para o ensino da matemática e por fim, tecer reflexões que visam a findar a discussão deste relato. Explanam-se, algumas adequações que se fizeram necessárias para o Plano de Desenvolvimento Individual - PDI, que flexibilizam os conteúdos do Currículo Comum, abreviado por CC, para alunos com deficiência.

Evitando-se qualquer generalização, nos limites das evidências deste artigo, constataram-se serem positivas para as AC em Matemática, o emprego de imagens, livros ilustrados, jogos didáticos, materiais visuais elaborados pelos professores, entre outros recursos visuais, que não somente os enunciados matemáticos.

\section{A GÊNESE DAS AC E O ATENDIMENTO EDUCACIONAL ESPECIALIZADO - AEE}

As AC são concebidas como individualizações dos métodos de ensino, dos conteúdos, do programa e sua temporalidade e da avaliação. A Lei de Diretrizes e Bases da Educação Nacional (BRASIL, 1996), menciona em seu art. 59, inciso I que os sistemas de ensino devem assegurar aos educandos técnicas, currículos métodos, organização e recursos educativos, bem como "recursos educativos e organização específica, para atender às suas necessidades”. Aos municípios do Rio Grande do Sul, competiu elaborar o Referencial do Território do Município - $\mathrm{RTM}^{2}$, com apoio dos

${ }^{1}$ Portadora de síndrome clínica, persistente e significativa da comunicação e interações sociais, deficiência na comunicação verbal e não verbal, ausência e reciprocidade social, falência em manter relações apropriadas ao seu nível de desenvolvimento (BRASIL, 2012), bem como a padrões restritivos e repetitivos de comportamentos, interesses e atividades. Manifesta-se sob a forma de comportamentos motores, sociais, comunicativos, sensoriais incomuns, ou estereotipados, interesses restritos e fixos. Apresentam atraso na fala ou não a desenvolvem.

${ }^{2}$ Pode ser solicitado pelos interessados ao Município de Gravataí, RS, por sua Secretaria de Educação. Fornecido às escolas por ícone de google drive, sendo atualizado permanentemente por formação continuada de professores. 
professores do CC e AEE. Trata-se de um documento que estabelece o currículo, alinhado ao Referencial Curricular Gaúcho - RTG (RIO GRANDE DO SUL, 2018), que por sua vez, fundado sob a Base Nacional Curricular Comum - BNCC. A Resolução N. 02 de 20 de dezembro de 2019 (BRASIL, 2019), instituiu as diretrizes curriculares nacionais, que deverão ser implementadas em todos os cursos destinados à formação docente, bem como as competências que a integram: 1) conhecimento profissional, 2) prática profissional e, 3) engajamento profissional, competências essas que se estenderam a todos os educadores.

O AEE tem como função organizar recursos pedagógicos e de acessibilidade, que visem eliminar barreiras, complementando e/ou suplementando a formação dos educandos, visando a independência e autonomia do aluno (RIO GRANDE DO SUL, 2018). Trata-se de garantir a acessibilidade ao currículo comum, empregando-se "estratégias, materiais, recursos e serviços que permitam ao estudante com deficiência" (RIO GRANDE DO SUL, 2018, p. 34), a participação de todas as atividades escolares.

Considero que a AC é uma flexibilização, mas não uma redução. Por conseguinte, adaptar não consiste em simplificar, por isso considero mais conveniente intitular como Adequações Curriculares - AC. Esta expressão converge para a empregada em Portugal, país em que o pesquisador desenvolveu seus estudos de doutorado, ficando o campo das adaptações a nível macropolítico, por não estarem ao alcance dos professores. A análise, no tópico a seguir, visa não a propor métodos, receitas, dicas, algo pronto, mas demonstrar que algumas AC, atendendo ao planejamento dos planos de aulas dos professores do CC, podem ser nada mais do que uma reinvenção de conteúdos.

Sob a ótica de Lyra e Custódio (2019), poderiam ser interpretadas como crenças, que podem influenciar a formação inicial dos futuros professores de Ciências e Matemática. Os autores afirmam ainda que existem uma pluralidade de crenças educacionais que exercem influência sobre as práticas dos professores. Neste artigo, quer-se problematizar que esta racionalidade, pode operar sobre as práticas pedagógicas, estabelecendo-se como métodos, procedimentos, condutas que podem ser tomadas como verdadeiras. Por verdade, assume-se a ótica foucaultiana, que a compreende como "conjunto de procedimentos que permitem a cada instante e a cada um pronunciar enunciados que serão considerados verdadeiros" (FOUCAULT, 1977, p. 233). Sob

Recebido em: $30 / 04 / 2020$ 
Edição Especial: XVI Encontro sobre Investigação na Escola - EIE

ISSN: 2595-4520 Vol. 4, n. 2. 2021

esses aspectos, pode-se perceber que as AC são provisórias, nunca definitivas e é nesta perspectiva que se insere este artigo.

\section{DELINEANDO ALGUNS MOMENTOS PEDAGÓGICOS}

Para cada aluno, existe uma anamnese, entrevista feita com o educando ao ingressar na escola. Este material, juntamente com o laudo médico e para alguns alunos psiquiátrico e/ou psicológico, compõem uma pasta, que de tempos em tempos deve ser lançada no sistema informatizado do município. É sob essa pasta que o professor do AEE, delineia o seu plano de trabalho.

O PDI - Plano de Desenvolvimento Individual, é um documento da escola, elaborado pelo professor do $\mathrm{CC}$ em conjunto com o professor do AEE, que define as ações necessárias já existentes e as que precisam ser desenvolvidas visando atender às necessidades educacionais especiais dos alunos. Para cada autista um autismo. Este documento promove o elo entre o RTM, RCG, BNCC, já mencionados. Além disso, orientam o currículo escolar, definindo as estratégias de aprendizagem individualizadas, que visam a flexibilização dos conteúdos do CC.

Os materiais e seus excertos foram escolhidos aletoriamente, com base naqueles que o pesquisador materialmente teve acesso. Os artefatos analisados refletem um ponto de vista singular do articulista, não sendo, portanto, definitivos. Visando a preservar o anonimato, os sujeitos de pesquisa foram identificados por nomes fictícios. A sala de recursos conta com jogos matemáticos, material dourado, jogos da memória, computadores (notebooks), uma pequena biblioteca com livros didáticos essenciais, como de Língua Portuguesa, Ciências, Inglês, Matemática, Literatura Infantil, dominós matemáticos, cartolinas, réguas, esquadros, brinquedos educativos para ensino de matemática, lápis de cor, cola, tesoura, papel, o Multiplano, o soroban, entre outros materiais.

Sob uma perspectiva foucaultiana, o relato assenta-se na seguinte questão: quais os benefícios que estas adequações trazem para os educandos?

\subsection{TECENDO OS RELATOS}

Recebido em: 30 /04/ 2020 
Cinco alunos foram atendidos entre maio/2019 a dezembro/2019, sendo dois de nível de gravidade autista leve, dois de nível moderado e um de nível severo: Pedro, Viseu, Felipe, Mário, Anderson, a seguir mencionados:

(PEDRO), autista leve, do $5^{\circ}$ ano do EF, frequente a todos os encontros, desenvolvia todas as atividades propostas, tanto pelo professor do $\mathrm{CC}$, como do AEE. Visava-se, em geral, reforçar o conteúdo aprendido em sala de aula. Explanou-se as frações: própria, imprópria e aparente, operações de frações envolvendo denominadores iguais, e denominadores diferentes em que se aplicava o m.m.c. - mínimo múltiplo comum. Reforçaram-se as operações de adição, subtração, multiplicação e divisão, envolvendo números decimais e números fracionários. Também se desempenhou atividades de equações do primeiro grau, envolvendo a incógnita x. O aluno escrevia empregando a simbologia matemática, e trazendo respostas corretas ao solicitado, o que demonstrava abstração matemática. Em conversa com o professor do CC de matemática, o aluno atendia a todas situações-problema propostas e conseguia acompanhar a evolução dos conteúdos. Não apresentava comportamentos que se remetiam imediatamente a uma pessoa autista, sendo imperceptível o déficit cognitivo nas tarefas escolares. A figura 01, a seguir, ilustra alguns enunciados matemáticos suportado por imagens, empregados no AEE, para o ensino de adição:

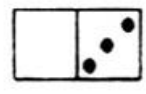

$0+3=3$
1. Para cada desenho, faça uma adição como no exemplo acima:

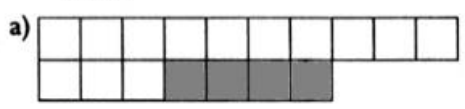

$13+4=$

Figura 1 - Excerto de atividade desenvolvida pelo professor do AEE.

(VISEU), autista leve, aluno do $7^{\circ}$ ano do EF, uma vez que conseguia compreender os conteúdos propostos pelo professor de matemática, tinha um interesse específico: trabalhar as formas geométricas. Nesse sentido avançou-se com a geometria plana. Estudo do ponto, reta, plano e figuras geométricas. Emprego da régua, esquadro, noção de ângulo e seus tipos e uso do compasso foram algumas atividades desenvolvidas com o aluno. Estudo dos triângulos e dos quadriláteros: paralelogramos, como o quadrado, retângulo e losango, e os trapézios, do tipo isósceles, escaleno e 
Edição Especial: XVI Encontro sobre Investigação na Escola - EIE

ISSN: 2595-4520 Vol. 4, n. 2. 2021

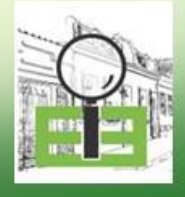

retângulo. Estudo do círculo e do pi (П), raio, corda, diâmetro. Apresentava resistência a ler e escrever. Preferia assistir a conteúdos matemáticos explanados em vídeos do youtube, orientados pelo professor. Com este aluno, obteve-se excelentes resultados, empregando-se o livro Matemática Ilustrada de Kirsteen Rogers e Tori Large da Porto Editora (ROGERS; LARGE, 2011). O livro aborda a matemática detalhando-a com ilustrações ligadas por setas a pequenos enunciados matemáticos. O que há de positivo no emprego do livro é o tempo para ensino e a resposta do aluno. O livro ilustra todos os procedimentos a adotar, passo a passo. O atendimento tem duração de 45 a 60 minutos, logo não há espaço temporal suficiente para abordar conteúdos de tal forma como são abordados na sala de aula. O próprio aluno disse ao educador, que estava apenas copiando o escrito no quadro. Nesse sentido, recorria-se novamente ao livro ilustrado, para o ensino deste conteúdo. Houve a necessidade de reforço sobre as dízimas periódicas e equações do primeiro grau, tal como evidenciado na figura 02, a seguir, extraída do caderno do aluno, para a realização das avaliações finais:

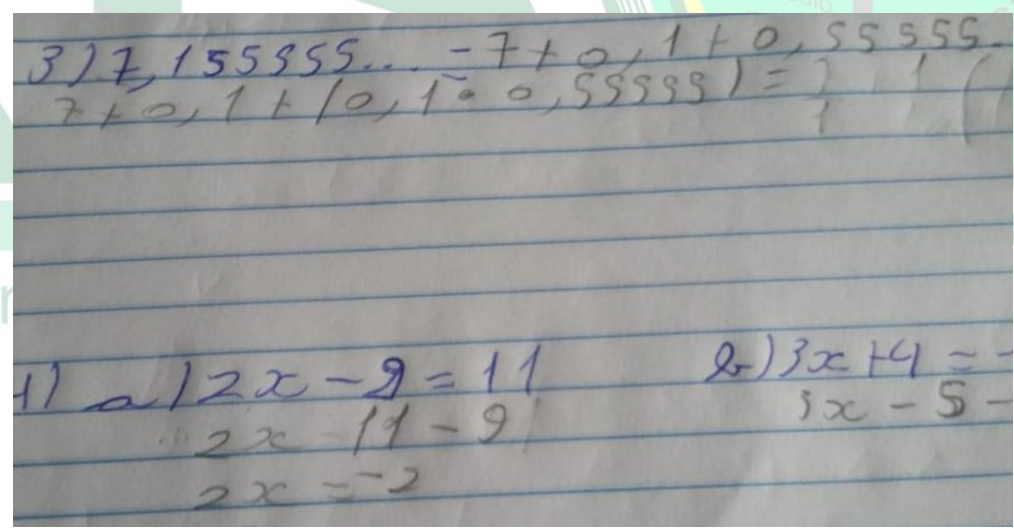

Figura 2 - Excerto do caderno do aluno.

Fonte: a pesquisa.

(FELIPE), autismo moderado, aluno do $2^{\circ}$ ano do EF, demonstrava evolução superior aos demais colegas de turma, pelos resultados comunicados ao professor do AEE. Sabia operar adição, subtração, multiplicação com números de 0 a 1000, enquanto os demais estavam operando até 50. Envolveu o interesse do aluno, o engajamento dos pais e do professor do AEE, uma vez que os conteúdos do CC não atendiam ao nível cognitivo do aluno. Tentou-se ir para a divisão, mas não houve espaço temporal para o

Recebido em: 30 /04/ 2020

127

Aceito em: 19/11/2020 
Edição Especial: XVI Encontro sobre Investigação na Escola - EIE

ensino pelo professor pesquisador. Havia uma espécie de contrato didático estabelecido com o aluno. Após o estudo, o educando desafiava o professor do AEE com labirintos, classificando-os como fáceis ou difíceis. Apresentava elevado nível de raciocínio, empregando os labirintos, da mesma forma com os jogos de memória.

Com (MÁRIO), $5^{\circ}$ ano do EF, autista nível moderado, trabalharam-se as atividades de adição, subtração envolvendo números com algarismos na $2^{\mathrm{a}}$ classe, empregando-se as mesmas laudas previamente elaboradas. Tal como (FELIPE), havia a necessidade de se estabelecer um contrato didático. Grande parte dos autistas, requerem algo como troca a respostas de situações-problemas. $O$ aluno gostava de usar o computador. Atendia às solicitações, desde que após pudesse "jogar" no computador por cinco minutos. Apesar de não estar diretamente relacionado à matemática, aprendeu a manusear o computador e já sabia o que cada tecla operava. Da mesma forma, (ANDERSON), autista de nível severo, de sétimo ano do EF, se apoiava no irmão, (MÁRIO), que por transposição, adequava os diálogos para seu nível de compreensão. (MÁRIO) não é alfabetizado, apresentava comportamentos agressivos, de higiene, bem como flapping das mãos periodicamente, além da agitação, promovendo um vaivém. Seu conhecimento restringia-se a escrever seu nome. Conseguiu-se no AEE, evoluir alguns conteúdos matemáticos, como o princípio da adição e subtração, envolvendo algarismos de 0 a 100. Utilizaram-se as mesmas laudas ilustradas, impressas, sendo escolhidos os exercícios que estavam em nível de compreensão do estudante, uma readequação do conteúdo a ser desempenhado com o aluno.

\section{PERCEPÇÃO SOBRE OS MOMENTOS PEDAGÓGICOS}

Limitado a estes relatos, é perceptível a necessidade da avaliação do aluno. Como o professor pode avaliar o nível de aprendizagem do aluno? Verificou-se que a cada momento pedagógico, novas AC eram reinventadas, em face às respostas dos educandos às tarefas propostas, e a imprevisibilidade do autismo. Isso leva-nos a refletir, que dadas as dificuldades apresentadas pelos educandos em sala de aula, apoiados por monitores, seria o AEE o ambiente ideal para a aprendizagem? Sob essa ótica, constatou-se que competia ao professor do AEE, juntamente com o professor do $\mathrm{CC}$, alinhar os conteúdos matemáticos, para que assim fosse estabelecido um PDI, tomando-se por base a anamnese do educando, os padrões comportamentais e sociais do aluno, a

Recebido em: 30 /04/ 2020

128

Aceito em: 19/11/2020 
interação com os demais colegas, bem como as respostas iniciais ao primeiro mês de ensino da matemática, e havendo necessidade, novas readequações dos conteúdos previamente planejados.

Autismo não é deficiência intelectual. O autista, para todos os efeitos legais é considerado Pessoa Com Deficiência - PCD, e tem direito ao atendimento multiprofissional (BRASIL, 2012), bem como o acesso a tecnologias assistivas, entendidas como uma série de recursos, dispositivos, metodologias, estratégias, equipamentos, produtos, que se destina, à participação e atividade da PCD (BRASIL, 2015), visando à independência e autonomia. Nesse sentido, entendo a Adequação Curricular como uma tecnologia assistiva. Por que digo adequação? Por estar mais ligada ao estabelecimento de estratégias para a aprendizagem em contexto do professor em nível escolar. Entendo que a discursividade das Adaptações Curriculares, situam-se em nível macropolítico, ligados ao governo municipal, estadual e federal, por conseguinte, não estão ao alcance do professor.

Voltando à nossa análise, e ao nosso problema de pesquisa, que benefícios as AC trouxeram aos educandos? Adequar não é reduzir o conteúdo textual, muito menos simplificá-lo. Está relacionada com outra complexidade que se remete a especificidade de diferentes autismos, que se não dominada por profissionais da área, resulta em falsas ou até equivocadas adequações. Não é de qualquer forma que se promove uma AC.

"As crenças didático-pedagógicas são manifestadas na prática docente pelo modelo de ensino e aprendizagem que o professor formador adota" (LYRA; CUSTÓDIO, 2019, p. 145). O que todas as experiências relatadas apresentavam em comum, bem como as AC promovidas, era o emprego de recursos visuais associados aos enunciados matemáticos, como forma ilustrativa, alternativas para a compreensão dos conteúdos matemáticos. Nenhuma AC foi elaborada pelo professor do AEE para tratar de alguma forma especial determinado aluno. Foram pensadas visando atender também aos neurotípicos ${ }^{3}$. Tendo em vista os materiais criados pelos professores do AEE estarem disponíveis na sala de recursos, muitos professores, empregavam o próprio material elaborado para ministrar a aula de maneira igualitária a todos os estudantes. Cita-se, o aluno (ANDERSON), que se sentia constrangido em sala de aula, pelo professor usar outro material, que não fosse o mesmo empregado com os neurotípicos, ou por ser tratado à parte, muitas vezes, acabava sendo ridicularizado pelos demais colegas, o que demonstrava para esta escola, ainda a necessidade de a escola conscientizar os demais alunos sobre o autismo. Logo, ao empregar-se o mesmo

\footnotetext{
${ }^{3}$ Assim como cego e vidente, surdo e ouvinte, convencionou-se autista e neurotípico.
} 
material com todos os alunos promovia-se maior interação social, uma vez, que algumas atividades passavam a ser desenvolvidas em grupo, algumas até sem acompanhamento integral do monitor.

Os autistas possuem elevada acuidade visual, sendo mais desenvolvida que em neurotípicos. Logo, foi positivo o emprego de figuras, objetos reais, fotos, desenhos, gráficos, entre outros recursos visuais. Na figura 01, o dominó, representa um texto regulado pela imagem, ou seja, a partir da imagem se extraia a operação, e na segunda imagem da figura 01, a imagem era determinada pelo enunciado, ou seja, a partir da operação matemática conseguia-se extrair a imagem. É um exercício que se sugere ao professor do AEE, ou seja, exercitar a criação de materiais. Grande parte das AC promovidas por professores despreparados, situam-se na imagem determinada pelo texto, sendo apenas complementares ao enunciado. Isso nos leva a refletir que as AC não podem ser elaboradas de qualquer forma. Ao mesmo tempo em que favorecem as pessoas autistas, propicia-se a aprendizagem de neurotípicos, eis que ambientes inclusivos.

\section{CONSIDERAÇÕES FINAIS}

O relato aqui descrito nos evidencia a necessidade de uma pedagogia visual para o ensino da matemática para alunos autistas, bem como o emprego de estratégias, que não especificas para cada autista, mesmo com a existência de diferentes autismos, mas que sob um contexto geral, interpelem, isto é, que conduzam a ação do professor e captem o maior número de sujeitos autistas e neurotípicos. Da gênese das $\mathrm{AC}$, ao relato dos momentos pedagógicos, vivenciados pelo professor como pesquisador, bem como as tecnologias assistivas que se mostraram promissoras para a aprendizagem da matemática por estudantes autistas, bem como, com a base nos PDI elaborados em conjunto com os professores do CC. Mostrou-se favorável a participação dos pais e da supervisão em conselhos de classe, onde são explanados pelos professores, os avanços de aprendizagem dos estudantes autistas, bem como o grau de interação com os demais colegas de classe.

No que tange a avaliação, estas são descritas em um parecer geral, que visa expor as potencialidades dos estudantes, os seus avanços em aprendizagem. Tudo isso baseado em avaliações e acompanhamentos sistêmicos, pelo professor do AEE. Além disso, os

Recebido em: 30 /04/ 2020 
Edição Especial: XVI Encontro sobre Investigação na Escola - EIE

ISSN: 2595-4520 Vol. 4, n. 2. 2021

erros tomados como novos construtos do conhecimento matemático. O quadro 01, a seguir, estabelece alguns resultados, estratégias para o ensino da matemática para estudantes autistas, que foram empregadas pelo professor do AEE, alinhados com o professor do CC. Importante frisar que o estudo visa elencar as estratégias de aprendizagem e não nos conteúdos do CC. Neste último, a elaboração obedece a BNCC, RTG e RTM, e as estratégias podem ser empregadas para mais de uma unidade temática, objeto de conhecimento e habilidades no campo da Matemática. O professor remete a AC para a supervisão escolar, e esta redistribui conforme a necessidade dos professores, podendo inclusive ser empregada em mais de uma área de conhecimento, como ocorreu no período de análise, para a Língua Portuguesa, ao se trabalhar textos matemáticos.

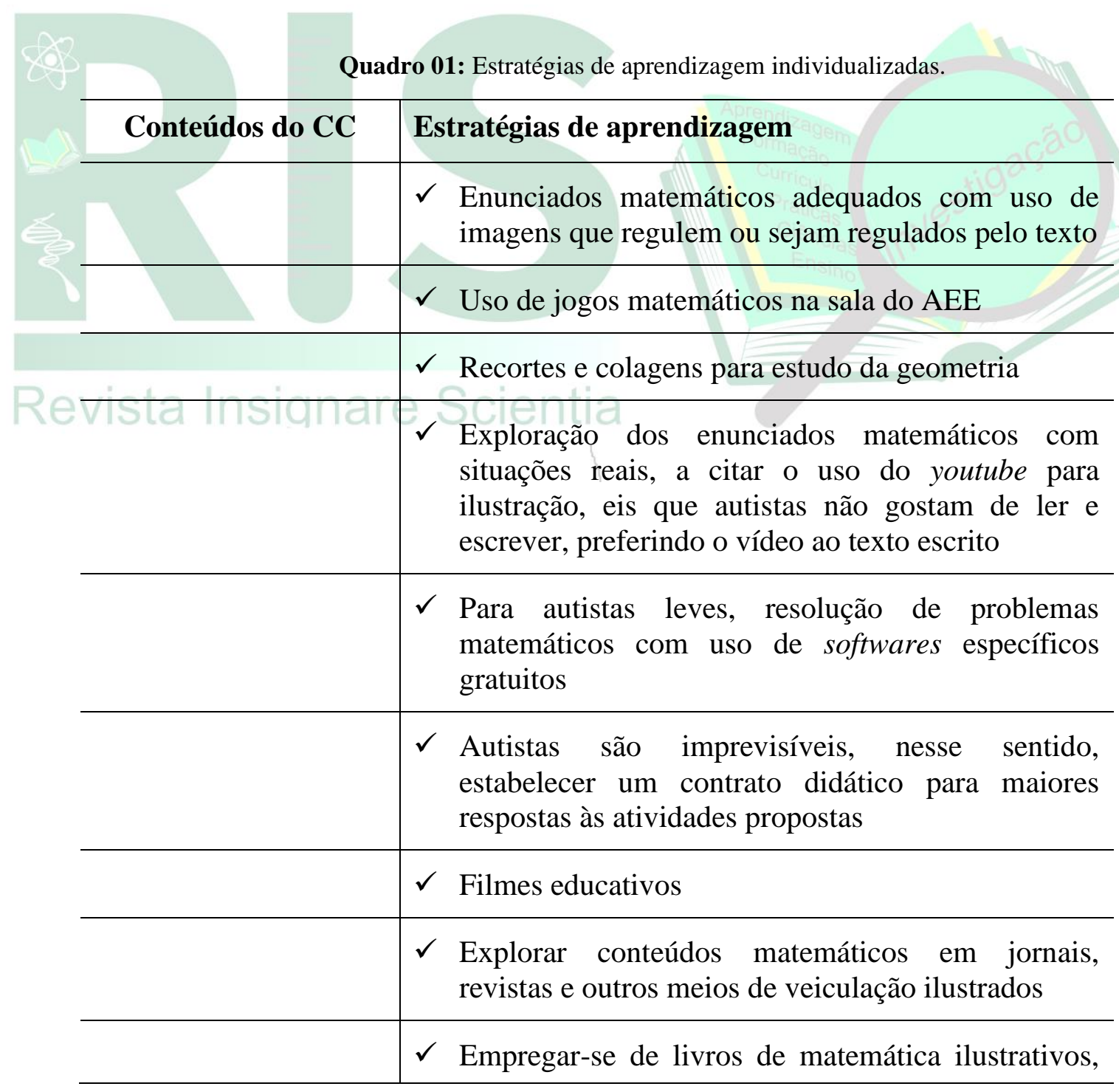


Edição Especial: XVI Encontro sobre Investigação na Escola - EIE

em complementação ao livro didático

\begin{tabular}{|c|c|}
\hline & em complementação ao livro didático \\
\hline & $\begin{array}{l}\checkmark \text { Utilizar réguas, compassos, esquadros, computador, } \\
\text { para estudo do ponto, reta, plano, figuras } \\
\text { geométricas, plana e espacial }\end{array}$ \\
\hline & $\begin{array}{l}\checkmark \text { Empregar-se de materiais concretos: material } \\
\text { dourado, Multiplano, Soroban, pranchas, cartões de } \\
\text { comunicação, figuras, desenhos, fotos, gráficos e } \\
\text { esquemas visuais }\end{array}$ \\
\hline & $\begin{array}{l}\checkmark \text { Participação do professor de matemática do CC, do } \\
\text { AEE, e se possível, com os pais e supervisão } \\
\text { escolar, para avaliação sistemática e emissão de } \\
\text { parecer da aprendizagem e interação social do } \\
\text { educando autista }\end{array}$ \\
\hline
\end{tabular}

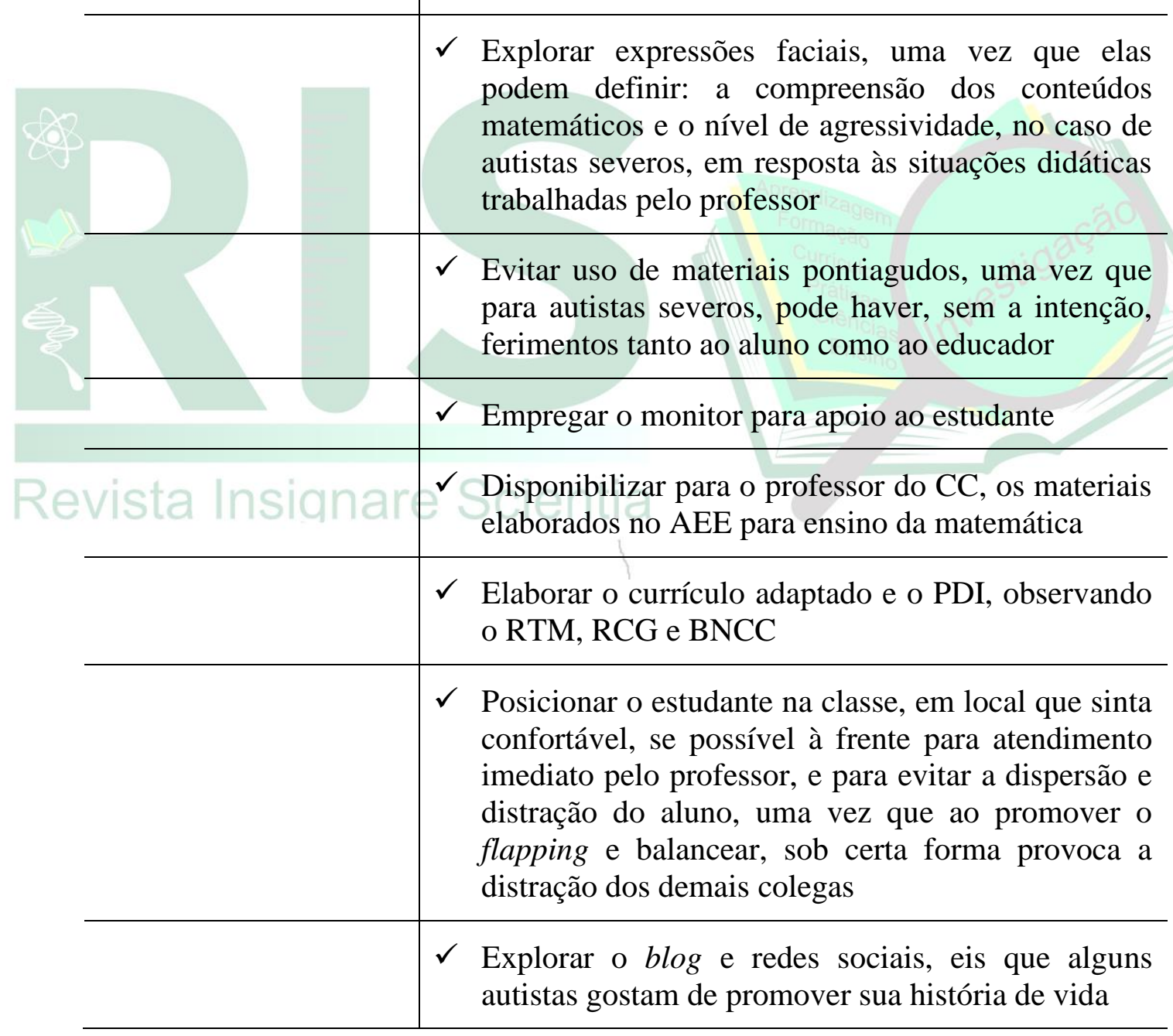

Fonte: a pesquisa. 
Edição Especial: XVI Encontro sobre Investigação na Escola - EIE

Sob o olhar foucaultiano (FOUCAULT, 1977), de forma alguma, as estratégias sugeridas pelo autor devem ser tomadas como algo pronto e acabado, sob a forma de receita. As AC são provisórias, sujeitas a reinvenções. O professor do AEE é ao mesmo tempo sujeito de sua pesquisa. Verificou-se que as AC não podem ser efetuadas de qualquer forma, pois requerem professores especializados em Educação Especial. Além disso, são reinventadas a todo instante, dado o grau de imprevisibilidade do autismo. Também se constatou que para a elaboração do PDI, por ser um documento da escola, solicita uma equipe multiprofissional: psicólogos, psiquiatras, professores do AEE, do CC, pais, supervisão escolar, enfim todos trabalhando de forma engajada e comprometida com a inclusão como propõem as politicas públicas, além do conhecimento, é claro, da matemática (BRASIL, 2012, 2015, 2019). O estudo busca não findar, mas abrir espeço para novas trocas de experiências, bem como, para que novas pesquisas sejam desenvolvidas na área do autismo, visando a contribuir para a educação desse tipo de alunado em ambientes de inclusão, e que as AC sejam não só meras reconfigurações de enunciados, ou do modo de agir do educador, mas sim promissoras para alunos autistas e neurotípicos.

\section{REFERÊNCIAS}

BRASIL. Lei No 9.394, de 20 de dezembro de 1996. Estabelece as diretrizes e bases da educação nacional. Disponível em:

<http://www.planalto.gov.br/ccivil_03/leis/19394.htm>. Acesso em: 21 mar. 2020.

Lei $\mathbf{N}^{\mathbf{0}} \mathbf{1 2 . 7 6 4}$, de 27 de dezembro de 2012. Institui a política nacional de proteção dos direitos da pessoa com transtorno do espectro autista; e altera o $\S 3^{\circ}$ do art. 98 da Lei no 8.112, de 11 de dezembro de 1990. Disponível em: <https://www.planalto.gov.br/ccivil_03/_ato2011-2014/2012/lei/112764.htm>. Acesso em: 19 mar. 2020.

Lei $\mathbf{N}^{\mathbf{0}}$ 13.146, de 06 de julho de 2015. Institui a lei brasileira de inclusão da pessoa com deficiência (Estatuto da pessoa com deficiência). Disponível em: <http://www.planalto.gov.br/ccivil_03/_ato2015-2018/2015/lei/113146.htm>. Acesso em: 21 mar. 2020.

Resolução $\mathbf{N}^{\mathbf{0}}$ 2, de 20 de dezembro de 2019. Define as diretrizes curriculares nacionais para a formação inicial de professores da Educação Básica e institui a Base Nacional Comum para a Formação inicial de professores da Educação Básica (BNCFormaçã0). Disponível em: <https://abmes.org.br/arquivos/legislacoes/RepublicadaResolucao-cne-cp-002-2019-12-20.pdf >. Acesso em: 21 mar. 2020.

Recebido em: 30 /04/ 2020 
Edição Especial: XVI Encontro sobre Investigação na Escola - EIE

FOUCAULT, Michel. (1977). Poder e saber. In: MOTTA, Manuel Barros da. (Org.).

Michel Foucault. Estratégia, Poder-Saber. Rio de Janeiro: Forense Universitária, 2003. p. 223-240.

LYRA, Letícia Ribeiro; CUSTÓDIO, José Francisco. O professor formador e suas crenças didático-pedagógicas. Revista Insignare Scientae, v. 2, n. 4, set./dez. 2019, p. 141-157, 2019.

RIO GRANDE DO SUL. Referencial Curricular Gaúcho, de 12 de dez. 2018.

Disponível em: <http:// http://curriculo.educacao.rs.gov.br/Sobre/Index>. Acesso em: 21 mar. 2020.

ROGERS, Kirsteen; LARGE, Tori. Matemática ilustrada. Porto: Porto Editora, 2011

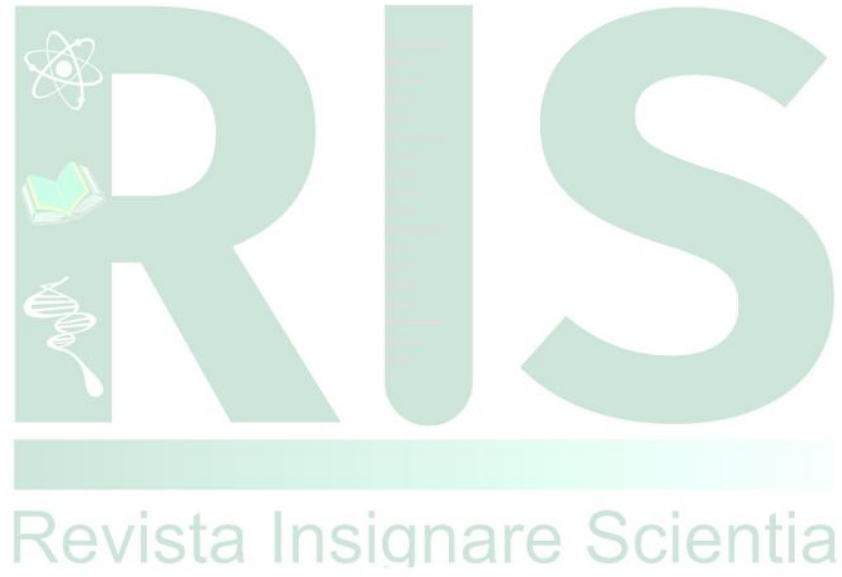

